\title{
Obesity due to prohormone convertase I deficiency
}

INSERM

\section{Source}

INSERM. (1999). Orphanet: an online rare disease and orphan drug data base. Obesity due to prohormone convertase / deficiency. ORPHA:71528

Prohormone convertase-I deficiency is the rarest form of monogenic obesity. The disorder is characterised by severe childhood obesity, hypoadrenalism, reactive hypoglycaemia, and elevated circulating levels of certain prohormones. 